DOI: https://doi.org/10.34137/jilses.684622

\begin{tabular}{ll}
\hline Geliş Tarihi: 06-02-2020 & Received: 06-02-2020 \\
\hline Kabul Tarihi: 16-04-2020 & Accepted: 16-04-2020 \\
\hline Makale Türü: Araştırma Makalesi & Research Type: Research Article \\
\hline Akay, D. S., Akca, G., Atik, A.D., Erkoç, F. (2020). Yaşam Bilimleri \\
Profesyonellerinin İklim Değişikliğinin Sağllk Üzerindeki Etkileri Konusunda \\
Eğitim İhtiyaçları Var Mi? The Journal of International Lingual Social and \\
Educational Sciences, 6 (1), 141-151. \\
DOI: https://doi.org/10.34137/jilses.684622
\end{tabular}

\title{
Yaşam Bilimleri Profesyonellerinin İklim Değişikliğinin Sağlık Üzerindeki Etkileri Konusunda Eğitim İhtiyaçları Var Mı?*
}

\author{
Dicle Seher AKAY ${ }^{1}$ Gülçin AKCA ${ }^{2}$ Ali Derya ATÍK ${ }^{3}$ Figen ERKOÇ $^{4}$ \\ Öz
}

Bu çalışmanın amacı yaşam bilimleri profesyonellerinin (hekim, hemşire, paramedik, veteriner hekim, eczacı, biyolog, bunların ara elemanları ile eğitimcileri) iklim değişikliğinin sağlık üzerindeki etkileri konusundaki temel bilgi düzeylerini ve farkındalıklarını araştırarak; eğitim ihtiyacı olup olmadığını tespit etmektir. Veri toplama görüşme tekniği ile, verilerin kantitatif analizi frekans ve yüzde hesaplamalartyla yapılmıştır. Bu amaçla 158 katılımcıya konu ile ilgili anket uygulanmıștır. Küresel iklim değişikliği konusunda bilgi sahibi olanlar \%41,1 (65) olmayanlar \%5,1(8), kismen bilgi sahibi olanların oranı \%53,8 (85); sağllk etkilerinden haberdar olanlar \%43,7 (69), olmayanlar \%6,3 (10), kısmen haberdar olanlar \%50 (79)'dir. Katılimclların iklim değişikliğinin sağlık üzerine etkileri konusunda bilgi kaynakları başlıca internet ve yazllı basındır. Türkiye'de küresel iklim değişikliğinin sağllk etkileri ve uyumdan sorumlu bir kurum olduğunu söyleyenlerin oranı \%5,7 (9), olmadığını ifade edenlerin oranı \%14,6 (23) ve bu konu hakkında bilgi sahibi olmayanların oranı \%79,7 (126)'dir. Sağlı üzerindeki etkileri konusunda hizmet içi eğitim veya herhangi bir kursa/seminere katılanların oranı \%8,2 (13) iken, katılmayanlar \%91,8 (145)'dir. Katılımcıların \%83,5 (132)'i eğitime ihtiyaç duyduğunu belirtmiştir. Sonuçlar yaşam bilimleri profesyonellerinin küresel iklim değiş̧ikliğinin olası sağlık üzerindeki etkilerine karșı eğitime ihtiyaç duyduklarını göstermekte ve bu alanda eğitim verilmesinin gerekli olduğu düşünülmektedir.

Anahtar Kelimeler: İklim değişikliği, yașam bilimleri, mesleki eğitim, eğitim ihtiyacı

\section{Do Life Science Professionals Need Training for the Effects of Climate Change on Health?}

\begin{abstract}
The aim of this study is to investigate point out the effects of climate change on health, but also to investigate the basic knowledge and awareness of life sciences professionals (doctors, nurses, paramedics, veterinarians, pharmacists, biologists and educators) whether the need for education. Quantitative analysis of the data was performed with data collection interview technique and frequency and percentage calculations. For this purpose, a questionnaire on the topic, developed by the researchers was applied to 158 participants. Those with knowledge about CC were $41.17 \%$ (65), without 5.1\% (8), partially knowledgeable 53.8\% (85); informed about health effects were $43.7 \%$ (69), not informed 6.3\% (10), partially informed 50\% (79). The internet and written media were the major sources of information for CC health effect to the participants. Of the respondents $5.7 \%$ (9) were aware that there is an institution in Turkey responsible for CC health effects, those not aware were $14.6 \%$ (23), and those who had no idea were $79.7 \%$ (126). Respondents who had training or any course/seminar concerning health impacts were $8.2 \%$ (13), not trained 91.8\% (145). Majority of respondents $83.5 \%$ (132) declared they need training. The results show that life science professionals need training against the effects of global climate change on possible health, and it is considered necessary to provide training in this field.
\end{abstract}

Key words: Climate change, life sciences, vocational education, training needs

\footnotetext{
* Bu çalışmanın bir kısmı "1st International Congress on Environmental and Animal Health: Linking Endocrine Disrupters, Epigenetics, Biotechnology for Cancer in Animals" adlı kongrede, 6-8 Nisan 2018 tarihinde, Ankara'da poster olarak sunulmuştur.

${ }^{1}$ Öğretmen, Millî Eğitim Bakanlığı, dicleseher@ gmail.com, https://orcid.org/0000-0002-0417-6463

${ }^{2}$ Doç. Dr., Gazi Üniversitesi, gulcin68@yahoo.com, https://orcid.org/0000-0002-8877-4144

${ }^{3}$ Dr. Öğr. Üyesi, Kilis 7 Aralık Üniversitesi, alideryaatik@kilis.edu.tr, https://orcid.org/0000-0002-5841-6004

${ }^{4}$ Prof. Dr., Gazi Üniversitesi, erkoc@ gazi.edu.tr, https://orcid.org/0000-0003-0658-2243
} 


\section{Giriş}

Hava durumu, yeryüzünün herhangi bir yerinde, herhangi bir zamanında gözlenen ve yaşanan atmosferik koşulların bütünüdür. İklim ise bu hava koşullarında uzun süreli (Dünya Meteoroloji Örgütü (WMO) tarafından bu süre ortalama 30 yıl olarak kabul edilmektedir) gözlenen değişimlerin ortalamasıdır. İklim, hava koşullarındaki uç değerleri, şiddetli hava olaylarını, bunların sıklık dağılımlarını ve değişkenliğini de kapsamaktadır. Birleşmiş Milletler İklim Değişikliği Çerçeve Sözleşmesi'nde (UNFCCC) iklim değişikliğii, karşılaştırılabilir bir zaman diliminde iklimde gözlenen doğal değişikliğe ek olarak, insanların doğrudan ya da dolaylı etkinlikleri ile atmosferin bileşiminin bozulması sonucu iklimde oluşan değişiklik biçiminde tanımlanmıştır (Çelik, Bacanlı \& Görgeç, 2008).

1900’lü yıllardan sonra artan sanayi faaliyetlerinin doğal çevreyi olumsuz yönde etkileyerek küresel iklim değişikliğini hızlandırdığı ifade edilmektedir (Swim, Clayton \& Howard, 2011). Artan enerji ihtiyacının başta fosil yakıtlardan karşılanması, yeşil alanların çeşitli sebeplerle azalması ve pek çok insan faaliyetleri sonucu (antropojenik), atmosferde doğal olarak bulunan metan $\left(\mathrm{CH}_{4}\right)$ ve karbon dioksid $\left(\mathrm{CO}_{2}\right)$ gazlarının yanı sıra sentetik kimyasalların (kloroflorokarbon-CFC) artmasına neden olmuştur. Sera etkisi yaratan bu gazlar iklim değişikliğine neden olmaktadır (Aydın, 2017). İklim değişikliği hava sıcaklıklarının artmasına, fırtına, sel, dolu gibi hava olaylarının sık sık ve şiddetli yaşanmasına, deniz seviyesi yükselmesine, kuraklıkların artmasına, asit yağmurları ile ormanların zarar görmesine, bazı hayvan türlerinin göç etmesine veya bazı türlerin neslinin tükenmesine neden olmaktadır. Özellikle son yıllarda yaşanan bu olumsuzluklar sadece yerel düzeyde değil küresel boyutta hissedilir hale gelmektedir. Dünya genelinde yaşanan ekstrem hava olayları ve bunlara bağlı olarak yaşanan olumsuzluklar iklim değişikliğinin dikkate alınması gereken ciddi bir sorun olduğunun kanıtıdır.

İklim değişikliği, yürütülen yaygınlaştırma aktiviteleri ve konferanslarla ülkelerin gündemine girmiş, varlığg kabul edilmiş, olası etkilerini önleme ve azaltma çalışmaları için politikalar geliştirilmiştir. İklim değişikliği 1979'da Cenevre'de düzenlenen I. Dünya İklim Konferansında görüşülmüş ve iklim değişikliğinin günümüze etkilerinden bahsedilerek geleceğe yönelik tehditleri vurgulanmıştır. İklim değişikliğini önlemeye yönelik en geniş katılımlı (189 ülke) iş birliği, 1997'de imzalanıp 2005'te yürürlüğü giren ve Türkiye'nin de 2008'de imzaladığı Kyoto protokolüdür (Türkeş, 2001). Süresi 2020 yılı sonunda dolacak olan Kyoto Protokolü yerini 2015 y1lında kabul edilen Paris Anlaşması'na bırakacaktır. Paris Anlaşması, iklim değişikliği ile mücadelede 195 ülkenin ortak katkılarını birleştirebilmiş olması sebebiyle önemlidir. Anlaşma, azaltım, uyum, finans, kayıp ve zarar, teknoloji geliştirme ve transferi, kapasite geliştirme, şeffaflık ve küresel envanter gibi hususlara ilişkin kararlar içermektedir (Çakmak, Doğan \& Hilmioğlu, 2017; Moosmann, Neier, Mandl \& Radunsky, 2017). Bu anlaşmalarla beraber artık ülkeler iklim değişikliğinin varlığını kabul etmekte ve uyum çalışmaları geliştirmektedir.

Yürütülen uyum çalışmalarından biri de iklim değişikliğinin sağlık üzerindeki etkilerini azaltmaya yönelik çalışmalardır. İklim değişikliğinin sağlık üzerinde doğrudan ve dolaylı olarak pek çok etkisi bulunmaktadır (Çelik vd., 2008). Kurumlar Arası İklim Değişikliği ve Sağlık Çalışma Grubu (2010), iklim değişikliğine bağlı olarak ortaya çıkan insan sağlığ 1 problemlerini şu şekilde sıralanmaktadır: Doğrudan etkisi; sıcak dalgaları, soğuk hava dalgaları, seller, fırtınalar ve aşırı hava olayları sonucunda gerçekleşmektedir. Dolaylı etkisi; enfeksiyon hastalıkları, sıcaklığa bağlı hastalıklar ve ölümler, kanser, kalp-damar hastalıkları, astım, solunum allerjileri, strese bağlı hastalıklar, nörolojik hastalıklar ve bozukluklar, vektörle taşınan ve hayvan konakçılı (vektörel) hastalıklar, su kullanımı ve besin temini yoluyla olmaktadır (URL-1, Atay, Tüvan, Demir \& Balta, 2012, Gürel \& Aslan, 2019; IPCC, 2014).

Ülkemizin üç tarafının denizlerle çevrili olması, yamaç özellikleri, coğrafi konumu ve farklı iklimlerin yaşanıyor olması nedeniyle, farklı bölgeleri iklim değişikliğinden farklı biçimlerde ve boyutlarda etkilenecektir (Öztürk, 2002). Dolayısıyla iklimde görülen ve görülmeye devam edecek olan değişimler, çevre ve halk sağlığını da etkileyecektir. Bu sebeple sağlık çalışanları ve konunun profesyonellerinin bu konuda eğitimine ihtiyaç duyulacaktır. Şehirlerde artan nüfus sebebiyle bireylerin çevreye adaptasyonu daha yüksek yaklaşımlar ile ele alınmalıdır. Özellikle iklim değişikliğinin sağlık üzerindeki etkilerini dikkate alacak olursak, bu konuda halk sağlığının korunması ve hastalıkların önlenmesi için farklı politikalar geliştirilmeli, sağlık personelleri iklim değişikliği sağlık etkileri konusunda yeterli ve kaliteli hizmet verebilir hale getirilmelidir (Polat, Yanıkoğlu \& Çetin, 2017).

Yaşam bilimleri profesyonellerinin (hekim, hemşire, paramedik, veteriner hekim, eczac1, biyolog, gıda mühendisi ile bunların ara elemanları ve eğitimcileri) iklim değişikliği konusunda sunacağı hizmetin kalitesi bu kişilerin alacağı eğitimin kalitesine bağlı olarak değişecektir. Bu çalışmada, yaşam bilimleri profesyonellerinin iklim değişikliğinin sağlık üzerindeki etkileri konusunda yeterli bilgi sahibi olup olmadıkları, konu hakkındaki farkındalıkları ve iklim değişikliğinin sağlık üzerindeki etkileri hakkında eğitim ihtiyacı olup olmadığı araştırılmıştır. Çalışmadan elde edilen sonuçların adaptasyon/uyum programlarına katkı sağlaması ve yaşam 
bilimleri profesyonellerinin iklim değişikliğinin sağlık üzerine olan etkileri hakkında farkındalıklarını artıracağı düşünüldüğünden çalışma önemli görülmektedir.

\section{Çalışmanın Amacı}

$\mathrm{Bu}$ çalışmanın amacı, iklim değişikliğinin sağlık üzerindeki etkilerini azaltma ve halkı bilinçlendirme konusunda önemli etkileri olan yaşam bilimleri profesyonellerinin iklim değişikliğinin sağlık üzerindeki etkileri konusundaki temel bilgi düzeylerini ve farkındalıklarını araştırarak; yaşam bilimleri profesyonellerinin eğitim ihtiyacı olup olmadığını tespit etmektir. Aynı zamanda çalışma, konu ile ilgili çözüm önerileri sunmak ve bu konu ile ilgili neler yapılabileceğine vurgu yapma amacı taşımaktadır.

Bu çalışmada iklim değişikliği ile ilgili strateji belgeleri ve iklim değişikliğinin sağllk üzerindeki etkileri konusunda yapılacak olan uyum çalışmaları incelenmiştir. Yaşam bilimleri profesyonellerinin, iklim değişikliğinin sağlık üzerine etkileri konusundaki farkındalıkları belirlenmeye çalışılmış ve araştırma sonunda araştırmanın çalışma grubunu oluşturan yaşam bilimleri profesyonellerinin görüş ve önerileri doğrultusunda ülkemizde bu konunun eğitimindeki mevcut durumun ortaya konması hedeflenmiştir.

\section{Yöntem}

\section{Araştırmanın Modeli}

Araştırmada betimsel araştırma yöntemlerinden tarama modeli kullanılmıştır. Araştırmaya konu olan belirli bir gruba ait bireylerin özelliklerini veya herhangi bir konuya ait yönelimlerini (yetenekleri, tutumları, fikirleri, inançları ve/veya bilgileri) tanımlamak amacıyla verilerin toplanması esasına dayanan tarama çalışmalarında, araştırmaya konu olan olay, birey ya da nesne kendi koşulları içinde ve var olduğu gibi tanımlanmaya, veriler özetlenmeye ve niteliklerine göre gruplandırılmaya çalışılır (Fraenkal, Wallen \& Hyun, 2009; Karasar, 2012).

\section{Çalışma Grubu}

Araştırmada Türkiye'nin belirli illerinden (Ankara, Adana, Trabzon, Balıkesir, İstanbul ve Aydın) bağlantı sağlayabildiğimiz çeşitli sağlık kurum ve kuruluşları ile bunların eğitim kurumlarında yer alan 158 yaşam bilimleri profesyonelleri yer almıştır. Araştırmaya katılan katılımcıların demografik özellikleri Tablo 1'de verilmiştir.

Tablo 1. Katılımcıların demografik özelliklerinin sayı ve yüzde dağılımları

\begin{tabular}{|c|c|c|c|}
\hline Demografik özellikler & & Sayı (f) & Yüzde (\%) \\
\hline \multirow[t]{4}{*}{ Cinsiyet } & Kadın & 102 & 64,6 \\
\hline & Erkek & 54 & 34,2 \\
\hline & Belirtmeyen & 2 & 1,2 \\
\hline & Toplam & 158 & 100,0 \\
\hline \multirow[t]{6}{*}{ Meslekteki Kıdem } & $1-5 \mathrm{y} 1 \mathrm{l}$ & 33 & 20,9 \\
\hline & $6-10 \mathrm{y} 1 \mathrm{l}$ & 30 & 19,0 \\
\hline & $11-15$ y1l & 34 & 21,5 \\
\hline & 16 yıl ve üzeri & 57 & 36,1 \\
\hline & Belirtmeyen & 4 & 2,5 \\
\hline & Toplam & 158 & 100,0 \\
\hline \multirow[t]{7}{*}{ Branş } & Hekim, Veteriner hekim, Dişçi & 31 & 19,6 \\
\hline & Ebe, Hemşire, Lab t., Anestezi t. & 60 & 37,9 \\
\hline & Paramedik, Aile sağlığı & 18 & 11,4 \\
\hline & Eczaci & 9 & 5,7 \\
\hline & Psikolog, diyetisyen, sağlık memuru vb. & 35 & 22,1 \\
\hline & Belirtmeyen & 5 & 3,3 \\
\hline & Toplam & 158 & 100,0 \\
\hline \multirow[t]{6}{*}{ Yaş } & $20-25$ yaş & 15 & 9,5 \\
\hline & $26-30$ yaş & 30 & 19,0 \\
\hline & $31-35$ yaş & 35 & 22,2 \\
\hline & 36 yaş ve üzeri & 73 & 46,2 \\
\hline & Belirtmeyen & 5 & 3,2 \\
\hline & Toplam & 158 & 100,0 \\
\hline \multirow[t]{4}{*}{ Öğrenim Durumu } & Lise & 1 & 0,6 \\
\hline & Ön lisans & 43 & 27,2 \\
\hline & Lisans & 70 & 44,3 \\
\hline & Yüksek Lisans & 16 & 10,1 \\
\hline
\end{tabular}




\begin{tabular}{lrr} 
Doktora & 24 & 15,2 \\
Belirtmeyen & 4 & 2,5 \\
Toplam & 158 & 100,0 \\
\hline
\end{tabular}

Tablo 1 incelendiğinde, araştırmaya 158 kişi katılmış olup, katılımcıların 102'si (\%64.6) kadın ve 54'ü (\%34.2) erkektir. İki kişi tarafından cinsiyet belirtilmemiştir. Katılımcıların yaş dağılımı; 20-25 yaş arası 15 (\%9.5) kişi, 26-30 yaş arası $30(\% 19)$ kişi, 31-35 yaş arası 35 (\%22.2) kişi ve 36 yaş ve üzeri 73 (\%46.2) kişidir. Beş kiş̧i tarafından yaş belirtilmemiştir. Katılımcıların meslek gruplarına göre dağılımı; hekim, veteriner hekim, dişçi olanlar 31 (\%19.6) kişi, ebe, hemşire, laboratuvar teknisyeni, anestezi teknikeri olanlar 60 (\%37.9) kişi, paramedik, aile sağlığı 18 (\%11.4) kişi, eczacı olanlar 9 (\%5.7) kişi ve diğer (psikolog, öğretmen, diyetisyen, sağlık memuru) 35 (\%22.1) kişidir. Beş kişi tarafından bu bilgi belirtilmemiştir. Katılımcıların hizmet süresi; 1-5 yıl 33 (\%20.9) kişi, 6-10 y1l 30 (\%19.0) kişi, 11-15 yıl 34 (\%21.5) kişi ve 16 yıl ve üzeri olanlar 57 (\%36.1) kişidir. Dört katılımc1 hizmet süresi belirtilmemiş̧tir. Katılımcıların eğitim durumu; lise mezunu olan $1(\% 0.6)$ kişi, ön lisans mezunu olanlar 43 (\%27.2) kişi, lisans mezunu olanlar 70 (\%44.3) kişi, yüksek lisans mezunu olanlar 16 (\%10.1) kişi ve doktora mezunu olanlar 24 (\%15.2) kişidir. Dört kişi tarafından eğitim durumu belirtilmemiştir.

\section{Veri Toplama Aracı}

Araştırmada veri toplama aracı olarak araştıııcılar tarafından geliştirilen anket kullanılmıştır. Anket hazırlanırken öncelikle küresel iklim değişikliğinin nedenleri, sonuçları ve sağlık üzerinde etkileri araştırılmış, araştırmanın amacına uygun olarak yaşam bilimleri profesyonellerine sorulması gereken sorular belirlenmeye çalışılmış ve anketin kapsam sınırları belirlenmiştir. Kapsam belirlendikten sonra bazı soruların açık uçlu, bazı soruların ise katılımcıların ifadelere katılma düzeyini belirleyebilmek için (evet/hayır/kısmen, katıldım/katılmadım, var/yok gibi) kapalı uçlu olarak hazırlanmasına karar verilmiştir. Ankette küresel iklim değişikliği konusunda bilgi sahibi misiniz? İklim değişikliğinin sağlık üzerindeki etkilerinden haberdar mısınız? Ülkemizde, küresel iklim değişikliğinin sağlık etkileri konusunda yapılan uyum çalışmaları konusunda yetkili bir kurum var mıdır? Küresel iklim değişikliğinin sağlık etkileri konusunda hizmet içi eğitime veya herhangi bir kursa/seminere katıldınız mı? Küresel iklim değişikliğinin sağlık etkileri konusunda yeterli bilgi ve beceriye sahip olduğunuzu düşünüyor musunuz? Küresel iklim değişikliği konusunda eğitime ihtiyacınız var mıdır? vb. sorular sorulmuştur. Anket ön çalışmasından sonra kapsam ve şekil geçerliği için üç alan uzmanının görüşlerine sunulmuştur. Bir alan uzmanı, bir eğitim uzmanı ve dil uzmanı olan akademisyenlerin görüşleri alınarak, ankette 14 soruya yer verilmiştir. Uzman görüşleri doğrultusunda yapılan değişiklikler ile ankete son şekli verilmiş ve anketin kapsam ve şekil geçerliği uzman görüşlerine göre sağlanmıştır.

\section{Veri Toplama Süreci}

Araştırma için T.C. Gazi Üniversitesi Etik Komisyonu tarafindan 05.06.2018 tarih ve 05 sayllı toplantıda etik kurul izni verilmiştir. Araştırmanın veri toplama süreci 2018 y1lında, etik kurul izin alındıktan sonra gerçekleştirilmiştir. Veri toplama sürecinde verilerin bir kısmı görüşme tekniği ile bir kısmı ise elektronik ortamda toplanmıştır. Katılımcılardan Ankara'da bulunan 104 kişi ile çalıştıkları kurumlarda (yataklı sağlık kurumu, laboratuvar, üniversite gibi) görüşülmüştür. Görüşme ve araştırmanın özelliği tümüyle katılımcılara açıklandıktan ve bilgilendirildikten sonra, katılımcıların onayları alınmıştır. Katılımcılar çalışmaya katılmak istediklerini sözel olarak ifade etmişlerdir. Görüşmeler ortalama 10'ar dakika sürmüştür. Ankara ili dışında bulunan katılımcılarla ise (54 kişi), sosyal medya, çevrimiçi anket ya da elektronik posta yolu ile irtibata geçilmiş ve veriler elektronik ortamda toplanmıştır.

\section{Verilerin Analizi}

Verilerin analizinde kapalı uçlu sorulardan elde edilen nicel veriler için basit betimsel istatistik (yüzde ve frekans) ve konu hakkında fikirlerini ifade edebilecekleri açık uçlu sorudan elde edilen nitel veriler için betimsel analiz yaklaşımı kullanılmıştır. Araşıırmada toplanan veriler öncelikle katılımcıların araştırma problemlerine ilişkin neler söylediği ya da hangi sonuçları ortaya koydukları belirlenmeye çalışılmıştır. Elde edilen nicel veri seti tablolar kullanılarak görsel hale getirilmeye çalışılmışıtır (sınıflama). Daha sonra nicel ve nitel veriler (katılımcıların ifadeleri) ve birbirleriyle ilişkileri belirlenmeye çalışılarak, ilişkiler yorumlanmış (ilişkilendirme) ve sonuçlara ulaşılmaya çalışılmıştır (Yıldırım \& Şimşek, 2011). Araştırma problemlerine uygun olarak temalar önceden belirlenmiş ve verilerin bu temalar altında özetlenerek yorumlanmasının uygun olacağı düşünülmüştür. Katılımcıların verdikleri yanıtlar, mümkün olduğu kadar özgün (orijinal) formuna sadık kalınarak (alıntılar yapılarak) temalar altında toplanmıştır. 


\section{Bulgu ve Yorumlar}

Araştırmadan elde edilen bulgular aşağıda sunulmuştur:

İklim değişikliği konusunda bilgi sahibi olduğunu ifade eden katılımcıların oranı \%41.1 (65 kişi), bilgi sahibi olmayanların oranı \%5.1 (8 kişi) ve kısmen bilgi sahibi olanların oranı \%53.8 (85 kişi)'dir (Tablo 2).

Tablo 2. Katılımcıların küresel iklim değişikliği konusunda bilgi sahibi olma durumları

\begin{tabular}{lrr}
\hline Küresel iklim değişikliği konusunda bilgi sahibi misiniz? & f & $\%$ \\
\hline Evet & 65 & 41,1 \\
Hayır & 8 & 5,1 \\
Kısmen & 85 & 53,8 \\
Toplam & 158 & 100,0 \\
\hline
\end{tabular}

İklim değişikliğinin sağlık üzerine olan etkilerinden haberdar olan katılımcıların oranı \%43.7 (69 kişi), haberdar olmayanların oranı \%6.3 (10 kişi) ve kısmen haberdar olanların oranı \%50 (79 kişi)'dir (Tablo 3). Katılımcıların gerek iklim değişikliği konusunda gerekse iklim değişikliğinin sağlik üzerine olan etkileri konusunda bilgi ve farkındalık düzeylerinin benzer olması verilerin birbiri ile uyumlu olduğunu göstermektedir.

Tablo 3. Katılımcıların iklim değişikliğinin sağlık üzerindeki etkilerinden haberdar olma durumları

\begin{tabular}{lrr}
\hline Iklim değişikliğinin să̆lık üzerindeki etkilerinden haberdar mısınız? & f & \% \\
\hline Evet & 69 & 43,7 \\
Hayır & 10 & 6,3 \\
Kısmen & 79 & 50,0 \\
Toplam & 158 & 100,0 \\
\hline
\end{tabular}

İklim değişikliğinin sağlık üzerine etkilerinden haberdar olduğunu ifade eden katılımcılara bilgi kaynakları sorulmuştur. Bilgi sahibi olan katılımcıların yararlandıkları bilgi kaynakları ise sırasıyla; internet (\%69.6), gazete (\%34.8), dergi (\%1.3), diğer (\%29.1) olarak tespit edilmiştir. Katılımcıların büyük bir çoğunluğunun iklim değişikliğinin sağlık üzerine etkilerini kitle iletişim araçları (bilgisayar, gazete, dergi gibi) üzerinden takip ettiği belirlenmiştir. Ancak katılımcılar kitle iletişim araçları dışında farklı kaynakları veya gözlem gibi kişisel tecrübelerini kullanarak da bazı bilgilere ulaştıklarını ifade etmişlerdir. Aşağıda katılımcıların farklı bilgi kaynaklarına doğrudan alıntılar yapılarak örnekler sunulmuştur.

K20: Zoonoz hastalıklar mesleki görevlerimiz arasında olduğu için genel takip yapıyoruz.

K33: Yaşayan insan hikâyelerinden takip ediyorum.

K64: Bulaşıcı hastalıkların sürveyansında, hastane başvurusunda.

K62-K65: Belgesellerden takip ediyorum.

K63: Çeşitli kitapları okuyarak takip ediyorum.

K60: Kendi bahçemden küresel iklim değişikliği etkilerini takip ediyorum.

K77: İklim değişikliği etkilerini doğanın kendisinden takip ediyorum.

K84: İklim değişikliğini takip edip yaşıyoruz.

Katılımcıların iklim değişikliği konusunda meslekleri gereği çevresindeki kişilerden, çeşitli kitaplardan, belgesellerden ve gündelik yaşamlarındaki gözlemlerinden çeşitli bilgilere ulaştığı görülmektedir. İklim değişikliğinin sağlık üzerine etkilerinden kısmen haberdar olduğunu ifade eden katılımcılar, yeterince bilgi sahibi olmama nedenlerini sırasıyla; yayın yetersizliği (\%56.4), yayınların düzenli olmaması (\%20.9), yayınlara ulaşılamaması (\%24.2), bilgi kaynaklarının çoğunlukla yabancı dilde olması (\%20.9) şeklinde ifade etmişlerdir.

Ülkemizde, küresel iklim değişikliğinin sağlık etkileri konusunda yapılan uyum çalışmaları ile ilgili yetkili bir kurum olduğunu ifade edenler 9 kişi (\%5.7), böyle bir kurum olmadığını ifade edenler 23 kişi (\%14.6) ve bu konu hakkında bilgi sahibi olmayanlar 126 kişi (\%79.7)'dir. Katılımcılardan küresel iklim değişikliğinin sağlık etkileri konusunda hizmet içi eğitim veya herhangi bir kursa/seminere katılanlar 13 kişi (\%8.2) iken katılmayanlar 145 kişis (\%91.8)'dir (Tablo 4). 
Tablo 4. İklim değişikliğinin sağlık etkileri konusunda eğitim alanların yüzdeleri

\begin{tabular}{lrr}
\hline $\begin{array}{l}\text { Küresel iklim değişikliğinin să̆lık etkileri konusunda hizmet içi ĕ̆itime } \\
\text { veya herhangi bir kursa/seminere katıldınız mı? }\end{array}$ & f \\
\hline Evet, katıldım & 13 & 8,2 \\
Hayır, katılmadım & 145 & 91,8 \\
Toplam & 158 & 100,0 \\
\hline
\end{tabular}

Konu ile ilgili hizmet içi eğitim veya herhangi bir kurs/seminere katılan 13 kişiden 9'u (\%69.2) çalıştığı kurum ya da bağlı olduğu birim tarafından bilgilendirilmiş, diğer 4 kişi (\%31.8) ise farklı bir kurum veya kuruluş tarafından bilgilendirilmiştir. Eğitim alan katılımcıların tamamı verilen eğitimin yeterli olmadığı ifade etmektedir.

Katılımcıların büyük çoğunluğu küresel iklim değişikliğinin sağlık etkileri konusunda yeterli bilgi ve beceriye sahip olmadıklarını 125 kişi (\%79.1) ifade ederken, 24 kişi (\%15.2) kendini yeterli görmektedir (Tablo 5). Dokuz kişi (\%5.7) bu konuda fikir belirtmemiştir.

Tablo 5. Küresel iklim değişikliğinin sağlık etkileri konusunda eğitime ihtiyaç duyanların oranları

\begin{tabular}{lrr}
\hline Küresel iklim değişikliğinin sağlık etkileri konusunda yeterli bilgi ve & f & \% \\
beceriye sahip olduğunuzu düşünüyor musunuz? & 24 & 15,2 \\
Evet & 125 & 79,1 \\
Hayır & 9 & 5,7 \\
Cevap belirtilmemiş & 158 & 100,0 \\
\hline
\end{tabular}

Küresel iklim değişikliği konusunda 132 kişi (\%83.5) eğitime ihtiyaç duyduğunu; 26 kişi (\%16.5) ise eğitim ihtiyacı olmadı̆̆ını ifade etmiştir (Tablo 6).

Tablo 6. Katılımcıların küresel iklim değişikliği konusunda eğitime ihtiyaç durumları

\begin{tabular}{lrr}
\hline Küresel iklim değişikliği konusunda eğitime ihtiyacınız var mıdır? & f & \% \\
\hline Evet, var & 132 & 83,5 \\
Hayır, yok & 26 & 16,5 \\
Toplam & 158 & 100,0 \\
\hline
\end{tabular}

Ayrıca katılımcıların bu konuda belirtmek istedikleri çeşitli hususlar aşağıda sunulmuştur. Katılımcılar hem kendilerinin hem de toplumun diğer kesimlerinde küresel iklim değişikliği konusunda yeterli bilgi sahibi olmadıkları için eğitim alması gerektiğini ifade etmişlerdir. Eğitim ihtiyacının karşılanması için çeşitli seminer, kurs, kamu spotu vb. etkinlikler düzenlemesi ile gerçekleştirilebileceği katılımcılar tarafından ifade edilmiştir. Katılımcıların iklim değişikliği konusunda eğitim ihtiyacına yönelik görüşlerine ait ifadelere aşağıda sunulmuştur:

K18: İklim değişikliği konusunda herkes bilinçlendirilmeli, toplumda sadece bir klsma değil herkese bu eğitim ve bilgilendirme verilmelidir.

K26: İklim değişikliği konusunda tüketicilerin ciddi anlamda bilinçlendirilmesi gerek.

K31: İklim değişikliği sadece kulaktan dolma bilgilerle (deodorantlar ozon tabakası inceltir gibi) öğrendiğimiz için bu konuda halkı bilinçlendirecek ĕgitimlerin önce ĕgitim kurumlarında daha sonra farklı meslek grupları için ĕgitimler seminerler tanımlanmalı, katılımlar zorunlu kılınmalıdır. Insanlar tarafindan yapılan doğa tahribatının geri dönüşü olmayan bir seviyeye geldiğini düşünmekteyim.

K33: Ikklim değişikliği kanser (cilt kanseri) gibi etkileri olduğu için kamu spotu tarzında kitle iletişim ile bilgilendirme yapılmalıdır.

K41: İklim değişikliği ile ilgili afişler hazırlanabilir, kamu spotuna daha çok yer verilebilir.

K57: BBC ve CNN gibi kanallarda iklim değişikliği ile ilgili belgeselleri var. Ulusal kanallarda bu değişikliği ve kurtarma yolları anlatılan güzel belgeseller ile toplumu bilinçlendirmek gerekir.

K71: Kurumlarda bu konu ile ilgili eğitim verilmeli.

K79: Toplumun bütün kesimlerinde özellikle okullarda ciddi eğitimler verilmelidir.

K85: Okullarda eğitim verilmeli, seminerler düzenlenmeli. 
İklim değişikliği konusunda eğitimin tek başına yeterli olmayacağı ve bu sorunun çözümüne bilimsel ve profesyonel yaklaşılmasının gerektiği katılımcılar tarafından ifade edilmektedir. Bu konu hakkında bazı katılımcıların görüşleri aşağıdadır.

K86: İklim değişikliğinin çözümü hakkında devlet politikaları oluşturulmalıdır.

K152: Multidisipliner yaklaşımla verilecek ĕgitim ile farklı alanlarda yetişmiş elemanlar, risk analizi, önlem alma, politika geliştirme gibi konularda ülkemiz koşullarını etkili ve doğru şekilde değerlendirebilecektir.

K155: İklim değişiyor. Buna etki eden faktörlerin biri insan kaynakl. Geri dönüşümsüz bir noktaya gelmemek için ise eğitim faaliyetleri sadece bir umut olur. Umut soyuttur. Somut olan temiz sanayi ve enerji kaynaklarını sunmayı kabul eden sermayenin yapacaklarıdır.

Katılımcılar tarafından iklim değişikliği konusunda vatandaşların bilinçlendirilmesinde eğitimin önemli olduğu vurgulanmış ancak yeterli olmadığ bildirilmiştir. İklim değişikliği ile mücadelede çeşitli yaptırımlar uygulanması, yeşil alanların arttırılması, bu konuda kurum ve kuruluşların işbirliği ile çalışması ve sorumluluk üstlenmesi, konunun önemle ele alınması katılımcılar tarafından düşünülmektedir. Burada ifade edilen konularla ilgili olarak bazı katılımcıların görüşleri aşağıda sunulmuştur.

K99: Insanlar bu konuda sosyal medya tarafindan daha çok bilgilendirilmeli, çevre kirliliği ve küresel ısınmaya sebebiyet veren kişilere cezai yaptırımlar uygulanmalı. Ağaçlandırma yapılmalı.

K90: Să̆lık bakanlı̆̆l ve diğer kurumlar dâhil ayrıca özel sektöründe dâhil olarak her vatandaş değil her insanın sorumluluğu içerisinde olduğu için öncülük eden bir kurum ya da kuruluşun olmasl gerekir.

K93: Tüm dünyanın yıllardır üzerinde konuştuğu konunun günümüz şartlarını düşününce ne kadar haklı olduğunu ortaya çıkardl. Güvenlikli zirve konusu bile olan konunun ilerdeki su savaşlarının habercisi olduğunu düşünüyorum. Üç tarafi su ile çevrili ülkemin bu konuyu daha ciddiye alması gerekir.

İklim değişikliğinin olası sonuçlarını engellemek ve etkilerini azaltmak için bireysel olarak yapılabileceklerin olduğunu ve bunun için çaba harcanması gerektiği katılımcılar tarafından ifade edilmiştir. Örnekler aşağıdadır:

K110: Gelecek nesillere sağlıklı ve yaşanabilir bir dünya bırakmak istiyorsak doğaya zarar vermek yerine doğayı güzelleştirmek için elimizden geleni yapmalıyı.

K119: Eğitim değil de kendimin ilgilenmesi gerektiğini düşünüyorum üniversite mezunu ve să̆lık görevlisi olarak konu ile daha çok ilgili ve bilgili olsam iyi olacağını düşünüyorum.

Elde edilen bulgular sağlıkla ilgili farklı alanlarda görev yapan katılımcılar ve verdikleri yanıtlarla sınırlıdır. Ancak yaşam profesyonellerinin iklim değişikliğine bağlı ortaya çıkabilecek vakalar, bunlara doğru ve zamanında müdahale edebilme eğitim ihtiyacının belirlenmiş olması, ileri de daha kapsamlı yapılacak çalışmalara 1şık tutabilir.

\section{Tartışma ve Sonuç}

Araştırmada elde edilen bulgular sonucunda, katılımcıların yarıya yakın kısmının iklim değişikliği hakkında bilgi sahibi olduğu belirlenmiştir. Ayrıca katılımcıların yarıya yakını, iklim değişikliğinin sağlık üzerine etkileri hakkında haberdar olduklarını ifade etmişlerdir. Katılımcıların eğitim seviyelerinin yüksek olmasının, iklim değişikliği konusunun görsel ve yazılı medyada aralıklarla da olsa yer almasının, katılımcıların farkındalıklarının yüksek olmasında etkili olduğu söylenebilir. Benzer şekilde, sağlık alanında çalışan veya öğrenim gören (hemşirelik bölümü öğrencisi, tıp fakültesi öğrencisi, aile hekimi gibi) katılımcılarla yürütülen çeşitli çalışmalarda da katılımcıların iklim değişikliği konusunda bilgi ve farkındalık düzeylerinin yüksek olduğu tespit edilmiştir (Albayrak \& Atasayan, 2015; Biçer \& Vaizoğlu, 2015; Ergin, Akbay, Özdemir \& Uzun, 2017).

Araştırmamızda iklim değişikliğinin sağlık üzerine etkileri konusunda bilgi kaynaklarının daha çok yazılı ve görsel medya ile sınırlı olduğu ve kişisel gözlemlerine dayandığı tespit edilmiştir. Bireylerin sosyo-bilimsel bir konu olan iklim değişikliği hakkında önemli bilgi kaynaklarının medya araçları olduğunu gösteren benzer araştırmalar bulgularımızı desteklemektedir (Biçer \& Vaizoğlu, 2015; Ergin vd., 2017). Elde edilen bu sonuçlar, bireylerin iklim değişikliği konusunda bilgi sahibi olması ve bilinçlenmesi konusunda medya araçlarına önemli görev ve sorumluluk düştüğünü göstermektedir. Araştırmadan elde edilen bilgi kaynaklarının sınırlı olması, düzenli olmaması gibi nedenlerle bireylerin doğru bilgiye ulaşamaması bulguları da dijital araçların ve medyanın görev ve sorumluluğunun ne kadar önemli olduğunu desteklemektedir.

Araştırmamızdan elde edilen diğer bir bulgu ise katılımcıların büyük bir kısmının iklim değişikliğinin sağlık üzerine etkileri hakkında kursa/seminere katılmadığıdır. İklim değişikliği ile ilgili eğitim alan katılımcılar ise verilen eğitimin içeriğinin yetersiz olduğunu ifade etmiştir. Katılımcıların yarıya yakını iklim değişikliğinin sağlık 
üzerine etkileri hakkında bilgi sahibi olmadığı veya kısmen bilgi sahibi olduğu ve öğrenim süreçlerinde iklim değişikliğinin sağlık üzerine etkileri hakkında düzenli bir eğitim almadıkları dikkate alınacak olursa, yaşam bilimleri profesyonellerinin bu konu hakkında eğitim gereksinimleri olduğu söylenebilir. Nitekim yapılan görüşmelerde katılımcılar, iklim değişikliğinin sağlık üzerine etkileri ve halkın adaptasyonu konusunda eğitime ihtiyaç duyduklarını ifade etmişlerdir. Benzer şekilde literatürde toplumun farklı kesimlerinin bu konuda eğitim ihtiyacı olduğu tespit edilmiştir (Albayrak \& Atasayan, 2015; Biçer \& Vazioğlu, 2015; Ergin vd., 2017; Lavey, 2019; Temelli, Kurt \& Keçeci Kurt, 2011, Atik \& Doğan, 2019). Liao vd., (2019) tarafindan yapılan araştırmada tıp fakültesi öğrencilerinin büyük bir oranda (\%80) iklim değişikliğinin sağlık etkileri konusunda yeterli bilgiye sahip olmadıkları, özellikle müdahale edebilirlik konusunda hazır olmadıkları belirlenmiştir. Araştırıcılar iklim değişikliği için kapasitenin geliştirilmesi gerektiğini ve eğitim alanında çabalarla eko-tıbbî okuryazarlık gelişiminin güçlendirilmesi gerektiğini vurgulamışlardır. Lavey’in (2019) araştırmasında sağlık ve diğer alanlarda çalışanların müdahale edebilirlik konusunda hazırlıklı olmadığı, konuyla ilgili eğitimlerin olması gerektiği ve kapasite geliştirilmesinin gerekliliği vurgulanmıştır. Bell'in (2010) çalışmasında pratisyen hekimlerin iklim değişikliği sağlık etkileri konusunda hazırlıklı olmalarını sağlamak için yerel, ulusal ve uluslararası seviyede yapılması gerekenler tespit edilmiş ve konu ile ilgili yeterli çalışma olmadığını, hekimlerin tam ve daha hızlı bir şekilde eğitilmesi gerektiğini, ulusal düzeyde, tıp eğitimi ve öğretiminin iklim değişikliği ve sağlıkla ilgili entegre, bölgeler arası multidisipliner kanıtları hılı ve esnek bir şekilde yansıtması gerektiğini ortaya koymuştur. Benzer şekilde Valois vd., (2016), yaptığı çalışma sonucunda, aile hekimlerinin iklim değişikliği ve sağlık konusunda iyileştirilmiş tıp eğitimine duyulan ihtiyaç ortaya konmuştur. Konuyla ilgili ülkemizde yapılan en güncel çalışma Kiraz'ın (2019) hazırladığı eğitim amaçlı sağlık modülü çalışmasıdır. Modülde iklim değişikliği, sağlık etkileri, yurt dışı çalışmaları ve Türkiye' de konuyla ilgili yapılacak ve yapılmış olan iklim değişikliği sağlık etkileri uyum çalışmalarına değinilmiştir. Ergin vd., (2017) iklim değişikliği ile ilgili eğitimi erken yaşlarda almanın önemli olduğunu ifade etmekle birlikte, tıp fakültesinde iklim değişikliğinin insan sağlığı üzerine etkileri hakkında ayrıntılı olarak ele alınması gerektiğini belirtmektedir. Araştırmada, tıp fakültesi öğrencilerinin iklim değişikliğinin neden olduğu bazı hastalıklar (sıtma vb.) hakkında yeterli bilgiye sahip olmadıkları tespit edilmiştir. Green vd., (2009) tıp öğrencilerinin iklim değişikliği konusunda hazırlık araştırmalarında, gelecekteki tıbbi işgücünün, iklim değişikliğinin sağlık etkilerinin önemli olduğu bir dönemde çalışacaklarını belirtmektedir. Probleme dayalı bir öğrenme yaklaşımı ile iklim değişikliği ve sağlık konusunun tıp müfredatına dahil edilmesi gerektiği, klinik tıp, koruyucu sağlık ve küresel sağlık üzerinde durulması, halk sağlığı için vaka çalışmaları üzerinde durulması gerektiği belirtilmiştir.

Wellbery vd., (2017) araştırmasında, hükümetler arası kuruluşlar, sağlık dernekleri ve mesleki kuruluşların iklim değişikliğinin sağlık etkileri sorunlarının üzerine eğilme konusunda hekimlerin hazırlanmasının özellikle önemli olduğunu vurgulamışlardır. Ancak tıp fakültelerinin müfredatlarının bu hedefe yönelik eğitim ihtiyacına hazır olmadığını belirtmişlerdir. Tıp eğitiminde müfredata iklim değişikliğinin dahil edilebileceği sağlık konularının bulunduğunu belirtmişlerdir. Bu bulgulara göre tıp fakültelerinde özellikle çevre sağlığı derslerinde, iklim değişikliğinin insan sağlığı üzerine etkileri ile ilgili konu içeriklerinin arttırılması ve müfredatın güncellenmesi önerilmektedir. Benzer şekilde iklim değişikliğinin doğrudan ve dolaylı sağlık üzerine etkilerinin öğretilmesi için hemşirelik bölümü ders programlarında iklim değişikliği konularına yer verilmesi gerektiği vurgulanmıştır (Biçer \& Vaizoğlu, 2015). Shezi vd., (2019) yaptıkları çalışmada, sağlık profesyonellerinin toplumun iklim değişikliğine adaptasyonunda (uyum) önemli roller üstlenebileceğini bulmuşlardır.

Araştırıcılar iletişimin bu alanda geliştirilmesini de önemsemektedir. Raminez (2017) araştırmasında, veteriner hekimlerin konuya hâkim olduklarını ancak vektörel bulaşan hastalıklar konusunda herhangi bir işbirliği geliştirilmediği konusunda fikir beyan etmiştir. İklim değişikliği ile mücadele ve halkın adaptasyonu için bütün tarafların birlikte çalışmasını, sağlık uygulayıcılarının eğitim ihtiyaçları ile iletişim becerilerinin geliştirilmesi gerektiğini belirtilmiştir. Nhamo ve Muchuru (2019) iklim değişikliğinin sağlık üzerindeki etkilerine uygun uyum önlemlerinin uygulanmasını, hava durumuna dayalı tahmin ve erken uyarı sistemleri geliştirilmesini, halk eğitimi ve bilinçlendirmenin önemli olduğunu, uygun politikaların ortaya konulması, gözetim, araştırma ve izleme ile halk sağlığı altyapısı ve teknolojisinin iyileştirilmesi gerektiğini ortaya koymuşlardır. McMichael, Woodruff ve Hales'in (2006) iklim değişikliği ve insan sağlığı, günümüz ve gelecekteki riskler çalışmasında, iklim değişikliğinin sağlık etkileri detaylı sunulmuş, bu konuda iklim değişikliğinin varlığının, gelecekteki olasılığı ve sağlıkla ilgili sonuçlarının araştırılmasının, uluslararası ve ulusal politika tartışmalarına önemli bir girdi olduğunu belirtmektedir. İklim değişikliğinin olumsuz sağlık etkilerinin kanıtı ve öngörüsü, planlanan uyarlanabilir stratejiler için öncelikleri göstereceğini ve esas olarak, önleyici politikalar için olan durumu güçlendireceğini belirtmiştir. Tüm bu etkilerin sürdürülebilirliğin gerçek anlamını daha iyi anlamamıza yardımcı olacağını ifade etmiş̧lerdir. Bu sonuçlar araştırmamızda da elde ettiğimiz, iklim değişikliği ile mücadele konusunda kamu kurum ve kuruluşlarının birlikte çalışması, bilimsel ve profesyonel yaklaşımların benimsenmesi gerektiği, bulgularını destekler niteliktedir. 
2015’te Sağlık Bakanlığı tarafından yayımlanan İklim Değişikliği Uyum Eylem Planında da yaşam bilimleri profesyonellerinin iklim değişikliği konusundaki farkındalığı, yapılacak müdahaleler ve alınacak önlemler konusunda önemli olduğu belirtilmiştir. Bu konuda sağlık sisteminin güçlendirilmesi gerektiği, sağlık sisteminin iyi çalışması, toplumun her kesimine eşit davranılması, tüm topluma koruyucu ve birinci basamak sağlık hizmetlerini sağlaması gerektiği, yeterli eğitim sağlanması, daha iyi ve daha kolay ulaşılabilir sağlık hizmetinin sunulması ve gerekli personel ile çalışma koşullarının iyileştirilmesi belirtilmiştir (URL-2).

Sonuç olarak, tüm bu veriler ışığında, iklim değişikliği etkilerinin topluma kazandırılması ve bilinçlendirilmesinde bütün iletişim araçlarının etkin olarak kullanılması gereklidir. Bu konuda herkes için yeterli ve gerekli kaynaklar sağlanmalıdır. İklim değişikliği kontrolü amacıyla kirlilik izleme, insan yaşamı açısından riskli durumlara ilişkin uyarılar verilerek halkı bilgilendiren uzman sistemlerin geliştirilmesi gerekmektedir. Konunun merkezinde olan sağlık çalışanları ve bunların eğitimcileri, iklim değişikliği ve sağlık üzerine etkilerine, müdahale edebilirlik konusunda yetkin hale getirilmelidir. İklim değişikliğinin sağlık üzerine etkileri konusunda yaşam bilimleri profesyonellerinin eğitim ihtiyacının karşılanması, toplum ve insan sağlığı açısından önemli bir yere sahip olacaktır. Yaşam profesyonellerinin iklim değişikliğine bağlı oluşacak sağlık problemleri hakkında bilgi ve farkındalık düzeylerinin arttırılması ile ileride karşılaşabilecekleri vakalar hakkında hazırlıklı olmalarına ve olası problemlerin erken fark edilmesine katkı sağlayacağı düşünülmektedir. Yaşam bilimleri profesyonelleri tarafindan fark edilen iklim değişikliğinin etkileri ile ortaya çıkan vakalar sayesinde, ilgili kurum ve kuruluşlar zamanında uyarılarak gerekli önlemler zamanında alınabilir. Görüldüğü gibi ulusal mevzuat ve uluslararası antlaşmalar iklim değişikliğinin uyum, azaltma, finans kaynakları, sosyo-kültürel boyutta ele alınması gerektiğini zorunlu kılmaktadır.

\section{Öneriler}

Araştırmamızdan elde edilen veriler ve konuyla ilgili yapılan diğer çalışmalara bakıldığında konuyla ilgili aşağıdaki önerileri sunabiliriz:

$\checkmark$ Gerek hizmet içi gerek kurs şeklinde sonrasında yeterlik belgesi verilip teşvik edilerek yaşam bilimleri profesyonelleri iklim değişikliği ve sağlık konusunda uzman pozisyona getirilmelidir.

$\checkmark$ Aile hekimleri özellikle hassas gruplar için bulaşıcı hastalıklar, ishal salgınlarında halkı bilinçlendirmeye yönelik girişimlerde bulunmalıdır.

$\checkmark$ Özellikle iklim değişikliğinin sağlık etkilerinden daha fazla etkilenecek olan hassas gruplar için takip ve izleme programları geliştirilmelidir.

$\checkmark \quad$ İlgili kurumların güçlendirilmesi için iklim değişikliği ve sağlık konusu ile ilgili uzmanlaşmış personel ve birimler oluşturulmalıdır.

$\checkmark$ Gerek tıp eğitimi programları (müfredat) başta olmak üzere, sağlıkla ilgili tüm bilim alanlarının eğitim müfredatlarında iklim değişikliği ve etkilerine yer verilmelidir.

$\checkmark$ Oluşturulan devlet politikalarının uygulaması konusunda tüm disiplinler arası kurum ve kuruluşlar işbirliği ve uyum içerisinde çalışmaları desteklenmelidir.

$\checkmark$ Toplumun her kesiminin ulaşabileceği güvenilir bilgi kaynakları oluşturulması ve açı erişime sunulmalidir.

\section{Kaynakça}

Albayrak A., \& Atasayan Ö. (Mayıs, 2015). Yerel düzeyde iklim dĕ̆işikliği farkındalı̆̆ analizi / Gebze Örneği. 2nd International Sustainable Buildings Symposium

Atay, H., Tüvan, A., Demir, Ö., \& Balta, İ. (2012). İklim değişikliğinin sağlık üzerine etkileri. İklim ve sağlık arasındaki ilişkilere genel bakış: Hastalıklar, hassas gruplar, adaptasyon ve öneriler. Meteoroloji Genel Müdürlüğü Araştırma Dairesi Başkanlığı. https://www.mgm.gov.tr/FILES/iklim/yayinlar/iklim-sagliketki.pdf

Atik, A.D., \& Doğan, Y. (2019) Lise öğrencilerinin küresel iklim değişikliği hakkındaki görüşleri. Academy Journal of Educational Sciences, 3(1), 84-100. Doi: 10.31805/acjes.569937

Aydın, F. (2017). Üniversite öğrencilerinin küresel ısınma hakkındaki bilgi düzeylerinin belirlenmesi. Journal of Social Sciences and Humanities, 1(1), 118-132

Bell, E. (2010). Climate change: what competencies and which medical education and training approaches? BMC Medical Education, 10(31), 1-8. Doi: 10.1186/1472-6920-10-31

Biçer, B., \& Vaizoğlu, S. (2015). Hemşirelik bölümü öğrencilerinin küresel iklim değişikliği hakkındaki bilgi ve farkındalıklarının belirlenmesi. Hacettepe Üniversitesi Hemşirelik Fakültesi Dergisi, 2(2), 30-43 
Çakmak, E., Doğan, T., \& Hilmioğlu, B. (Kasım, 2017). İklim değişikliği sürecinde Paris Anlaşması'nın rolü ve Türkiye'nin konumu, VII. Ulusal Hava Kirliliği ve Kontrolü Sempozyumu, Antalya-Türkiye

Çelik S., Bacanlı, H., \& Görgeç, H. (2008). Küresel iklim değişikliği ve insan să̆lı̆̆ına etkileri, Telekomünikasyon Şube Müdürlüğü. https://mgm.gov.tr/FILES/genel/makale/11_kureseliklimdegisikligietkileri.pdf

Ergin, A., Akbay, B., Özdemir, C., \& Uzun, S.U. (2017). Tıp fakültesi öğrencilerinin küresel ısınma ve sağlığa etkileri ile ilgili bilgi, tutum ve davranışları. Pamukkale Tlp Dergisi, 10(2), 172-180. Doi: 10.5505/ptd.2017.15428

Fraenkel, J.R., Wallen, N.E., \& Hyun, H. (2009). How to design and evaluate research in education (7th Ed.). San Francisco: McGraw-Hill

Gürel, Z., \& Aslan, D. (2019). Halk sağlığı bakış açısıyla gıda kaynaklı krizler ve önleme yaklaşımları. Türk Hijyen ve Deneysel Biyoloji Dergisi, 76(3), 361-376. Doi: 10.5505/TurkHijyen.2019.34711

IPCC. (2014). Climate Change 2014: Synthesis Report. Contribution of Working Groups I, II and III to the Fifth Assessment Report of the Intergovernmental Panel on Climate Change [Core Writing Team, R.K. Pachauri and L.A. Meyer (eds.)]. IPCC, Geneva, Switzerland, 151

Karasar, N. (2012). Bilimsel araştırma yöntemi: Kavramlar, ilkeler, teknikler. Ankara: Nobel

Kiraz, E. (2019). İklim değişikliğinin insan să̆lı̆̆ına etkileri, Ankara: İklim Değişikliği Eğitim Modülleri Serisi

Lavey, W.G. (2019). Teaching the health impacts of climate change in many American higher education programs. International Journal of Sustainability in Higher Education, 20(1), 39-56. Doi: 10.1108/IJSHE-04-20180062

Liao, W., Yang, L., Zhong, S., Hess, J., Wang, Q., Bao, J., \& Huang, C. (2019). Preparing the next generation of health professionals to tackle climate change: Are China's medical students ready? Environmental Research, 168, 270-277. Doi: 10.1016/j.envres.2018.10.006

McMichael, A., Woodruff, R., \& Hales, S. (2006). Climate change and human health: present and future risks. Lancet, 367(9513), 859-69. Doi: 10.1016/S0140-6736(06)68079-3

Moosmann, L., Neier, H., Mandl, N., \& Radunsky, K. (2017). Implementing the Paris Agreement - New Challenges in view of the COP 23 Climate Change Conference, Study for the ENVI Committee, European Parliament, Policy Department for Economic and Scientific Policy, Brussels.

Nhamo, G., \& Muchuru, S. (2018). Climate adaptation in the public health sector in Africa: Evidence from United Nations Framework Convention on Climate Change National Communications. Journal of Disaster Risk Studies, 11(1), 644

Öztürk, K. (2002). Küresel iklim değişikliği ve Türkiye’ye olası etkileri. Gazi Üniversitesi, Gazi Eğitim Fakültesi Dergisi, 22(1), 47-65

Polat, Y., Yanıkoğlu, A., \& Çetin, H. (2017). İklim değişikliğinin sivrisinek kaynaklı hastalıklar üzerine etkisi. Anadolu Universitesi Bilim ve Teknoloji Dergisi, 6(2), 55-63. Doi: 10.18036/aubtdc.296680

Raminez, B. (2017), Support for research towards understanding the population health vulnerabilities to vectorborne diseases: increasing resilience under climate change conditions in Africa. Infectious Diseases of Poverty, 6, 164. Doi: 10.1186/s40249-017-0378-z

Shezi, B., Mathee, A., Siziba, W., Street, R.A., Naicker, N., Kunene, Z., \& Wright, C. Y. (2019). Environmental health practitioners potentially play a key role in helping communities adapt to climate change. BMC Public Health, 19(54), 1-8. Doi: 10.1186/s12889-018-6378-5

Swim, J. K., Clayton, S., \& Howard, G. S. (2011). Human behavior alcontributions to climate change psychological and contextual drivers. American Psychologist, 66(4), 251-264. Doi: 10.1037/a0023472

Temelli, A., Kurt, M., \& Keçeci Kurt, S. (2011). İlköğretim öğretmenlerinin küresel 1sınmaya ilişkin görüşleri. Kuramsal Ĕgitim Bilim Dergisi, 4(2), 220-208

Türkeş, M. (2001). Küresel iklimin korunması, iklim değişikliği çerçeve sözleşmesi ve Türkiye. TMMOB Makina Mühendisleri Odası, Süreli Teknik Yayın, 61, 14-29

URL-1: http://unfccc.int/2860 
URL-2: T.C. Sağlık Bakanlığı (2015). İklim değişikliğinin sağlık üzerine olumsuz etkilerinin azaltılması ulusal programı ve eylem planı, Ankara

https://hsgm.saglik.gov.tr/depo/birimler/cevresagligi/2ced/iklimdeğişikliği/Iklim_Degisikligi_Eylem_Pla ni.pdf

Valois, P., Blouin, P., Ouellet, C., Renaud, C.S., Langer, D., \& Gosselin, P. (2016). The health impacts of climate change: a continuing medical education needs assessment framework. JCEHP, 36(3), 218-225. Doi: 10.1097/CEH.0000000000000084

Wellbery, C., Sheffield P., Timmireddy K., Sarfaty M., Teherani A., \& Fallar R. (2018), It's time for medical schools to introduce climate change in to their curricula. Academic Medicine, 93(12), 1774-1777. Doi: 10.1097/ACM.0000000000002368

Yıldırım, A., \& Şimşek, H. (2011). Sosyal bilimlerde nitel araştırma yöntemleri, (8. Baskı). Ankara: Seçkin Yayıncilik

\section{Extended Abstract}

Climate change (CC) is the most important global environmental problem of concern, affecting human and environmental health. Significant risks exacerbated by rising temperature extremes will continue, IPCC, for centuries even if the global mean temperature is stabilized, future threats are expected as CC interacts with other stressors. Multidisciplinary and international collaboration is required both in research and policy making areas, at EU and UN levels since climate/energy are priorities. The 1992 United Nations Framework Convention on Climate Change (UNFCCC) and its 1997 Kyoto Protocol, the National Adaptation Plan (NAP) process under the convention, builds on the National Adaptation Programmes of Action (NAPA) process. NAP process, as a framework, the present guidance aims to ensure that the health sector works with partners in the environment and other related communities. NAP aims to process for identifying national strategic goals for building health resilience to climate change and managing the health risks of climate change. The health operational levels: environmental health, communicable disease control, health emergency preparedness require all health workers/professionals under the the "One Health" approach to be trained and ready to take responsibility for adaptation per NAP. Public health teams at the local, regional, and national levels will share responsibility for implementation. Therefore, developing and supporting training and educational activities, including awareness raising activities (e.g. briefings or presentations) about the health risks of CC for public health professionals are crucial for implementation. Medical school curricula are underway to plan climate-health topics to be included by 2020 and that climate-health is integrated into all aspects of medical education by 2025 . The aim of this study is to investigate point out the effects of $\mathrm{CC}$ on health, but also to investigate the basic knowledge and awareness of life sciences professionals (doctors, nurses, paramedics, veterinarians, pharmacists, biologists and educators)whether the need for education. Research also aims to present solutions to the issue and to emphasize what can be done about it. A questionnaire was prepared to determine the level of knowledge of life sciences professionals about health impacts of climate change in determining the need for education. Quantitative analysis of the data was performed with data collection interview technique and frequency and percentage calculations. For this purpose, a questionnaire on the topic, was applied to 158 participants. Those with knowledge about CC were $41.17 \%$ (65), without $5.1 \%$ (8), partially knowledgeable $53.8 \%$ (85); informed about health effects were $43.7 \%$ (69), not informed $6.3 \%(10)$, partially informed $50 \%(79)$. Web and written media were the major sources of information for CC health effect to the participants. Of the res 5.7\% (9) were aware that there is an institution in Turkey responsible for CC health effects, those not aware were $14.6 \%$ (23), and those who had no idea were 79.7 (126). Respondents who had training or any course/seminar concerning health impacts were 8.2\% (13), not trained $91.8 \%$ (145). Majority of respondents $83.5 \%$ (132) declared they need training. Results show that life science professionals need to be trained against the possible health effects of global climate change and that training should be provided in this field. This research also aims to present solutions to the issue and to emphasize what can be done about it. Today, the most important and irreversible environmental problem, global climate change, is discussed in line with the United Nations Framework Convention on Climate Change (UNFCC, 1994) and whether life science professionals have training needs for adaptation to $\mathrm{CC}$. 